\title{
A Study of Corporate Travel Management in Selected South African Organisations and a Conceptual Model for Effective Corporate Travel Management
}

\section{Berendien Lubbe}

Department Tourism Management, University of Pretoria

\begin{abstract}
South African corporations with a substantial travel expenditure of between R1 million and R300 million per annum are faced with two main issues. The first is the management and control of travel expenditure and the second is the management of the travel process to ensure required service levels at an optimum cost-benefit ratio. The corporation depends heavily on numerous interactive relationships to achieve this. In this article the key elements of corporate travel management are identified and the results of a survey conducted on the way in which corporate travel is managed in terms of each of these elements in selected South African organisations is reported. A conceptual model, based on a "soft value management model" which highlights conflicting values of participants and their commitment to goals is proposed as a foundation on which further research can be conducted.
\end{abstract}

JEL G30

\section{INTRODUCTION}

Corporate travel is that segment of the business travel market that can be described as travel undertaken by the employees of a particular organisation that has a substantial travel volume. Travel arrangements are generally consolidated into a centralized function that falls under a specific department or in many instances includes the establishment of a separate Corporate Travel Department that oversees the entire travel programme. One of the primary functions of such a department is to consolidate the travel volume to obtain leverage from travel providers such as airlines, hotels and car rental firms in the negotiation of contracts at reduced prices (Bell \& Morey, 1995). It is generally nondiscretionary travel because business travellers have little influence over where, when, how and how long to travel. 
In contrast to corporate travel, travel undertaken by the employees of small to medium size enterprises often lacks the volume of travel business to negotiate preferred rates from travel suppliers. These travellers generally make their travel arrangements through a retail travel agency as independent business travellers, although companies such as South African Airways has introduced, through its website www.flysaa.com, a facility for the management of travel for small and medium sized businesses. On the other hand, corporations with substantial travel portfolios generally use the services of one or more contracted travel management companies (TMC) to handle all their travel requirements. Thus, the difference between the independent business traveller and the corporate traveller lies in the way they make their travel arrangements. The independent business traveller generally makes his travel arrangements through a retail travel agency, as the leisure traveller would do, while the corporate traveller makes his arrangements via his organisation through a contracted TMC. The TMC is essentially a travel agency that specializes in corporate travel and provides a range of specialized services to the corporate client.

In South Africa approximately 40 per cent of the total travel market can be considered corporate or business-related (Palapies, 2001). It is expected that by 2003 more than half of the travel business in South Africa will be driven by corporate travel. Corporate travel spending for large organisations in South Africa can run from anything between R1 million and R300 million per annum and these costs steadily increase because, in most cases, travel and entertainment expenditure is not incurred by purchasing professionals but by the travellers themselves. The pre-eminent concerns of these travellers are not necessarily the cost involved but their own convenience and esteem while they are travelling (Gilbert \& Morris, 1995; Mason \& Gray, 1995).

Frequent travellers often consider themselves experts on making travel arrangements and will use their own discretion in the selection of hotels, airlines and car rental companies. As a result organisations often see travel as an uncontrollable expense. With the introduction and proliferation of online corporate booking tools which, according to a survey conducted in the USA, account for significant savings on travel costs (http://getThere.com [May 30, 2002]); the increasing rate of adoption of technology by consumers (Chircu, Kauffman \& Keskey, 2001); and the introduction of management fees by the travel management companies, the pressure to implement cost-saving strategies in corporate travel is mounting. These changes have also meant that the role of the travel supplier and the travel management company has changed fundamentally with traditional travel servicing making way for partnership agreements with corporate clients. 
In summary, two main issues face the corporate sector. The first is the management and control of travel expenditure and the second is the management of the travel process to ensure required service levels at an optimum cost-benefit ratio. The corporation depends heavily on numerous interactive relationships in facing these issues and achieving their goals (Wilkinson, 2001). These include the travellers, top management, travel suppliers and the travel management companies. Travellers are expected to comply with travel policies and top management must support the goals of travel management for it to be effective. The travel supplier and travel management company need to understand the issues that face the corporate client so that they can maintain their position as an integral partner in the travel management process. In this article the results of a survey conducted on the way in which corporate travel is managed in selected South African corporations is reported and a conceptual model, based on the interrelationships of the various roleplayers in corporate travel is proposed for its effective management.

\section{CORPORATE TRAVEL MANAGEMENT}

In contrast to the popular perception that travel expenditure cannot be efficiently controlled, Bartholomew (1995) and Ravenall (2002) suggests that travel and entertainment is one of the largest controllable expenses after salaries and information technology and that four opportunities exist for organisations to control travel and entertainment expenditure:

- Before the expense is incurred

- When making the reservation and at the point of sale

- When the expense item is paid

- When expense reports are prepared, audited and processed.

The only way to use these opportunities is to implement an effective travel management programme. According to academics such as Bell and Morey (1997), travel management companies such as American Express (Bunge, 2001) and consulting specialists such as International Corporate Travel Solutions (Ravenall, 2002), four core activities form the cornerstones of such a programme:

- The development of a travel policy and procedures of implementation

- The consolidation of travel management information

- The establishment of an effective payment system through the use of a centralised travel expenditure processing system such as a corporate credit card

- The careful selection of a travel management company. 
Furthermore Wilkinson (2001) stresses the importance of working relationships in effective corporate travel management: "Travel management has never been for the faint of heart. It requires staying on top of numerous interactive working relationships. It is designed to reconcile a company's policies and traveller's preferences and to process that purchasing dynamic through a series of suppliers." (Wilkinson, 2001: 10).

\section{The travel policy}

The major purpose of the travel policy is to keep the cost of corporate travel within predictable and realistic parameters and to save the organisation money. It also serves a secondary purpose of allowing travellers to understand exactly what the limitations are in terms of choices and alternatives (Gilbert \& Morris, 1995). The travel policy should include three categories of information: the procedure and guidelines for making travel arrangements; reporting procedures for expenses incurred; and the way in which the policy should be distributed to employees for easy reference. Ravenall (2002) maintains that a regularly updated and enforceable travel policy is essential for effective travel management. A travel policy highlights the relationship between the company and its travellers. In travel policy compliance or non-compliance, conflicting values and goals can emerge between management and travellers.

\section{Travel management information}

An organisation should expect proactive and quality management reporting and access to data. On a practical level a corporate travel reservation may have many components, including everything from the passenger name, routes, duration, fares, rates, frequent flyer numbers and even special meal requirements. Computer software programmes can provide reports on who goes where, how much an individual spends, if lower fares were offered and refused and much more (Limone, 2000). The consolidation of information on travel patterns and expenditure forms the basis of management reporting and allows the organisation to use the information to negotiate best buys, direct travellers to best buys and identify leaders and 'laggards' (Bunge, 2001). With current technology capabilities such as the Extranet, data can be accessible to the organisation and the travel management companies, and may also include preferred suppliers such as airlines, car rental companies and hotels (Buhalis, 2003). Typically the breakdown of travel expenditure for a large organisation in South Africa would be divided into airline tickets, accommodation, car rental and sundries as shown in Figure 1. This division of expenditure is based on Gomes-Costa and Birns (2003) and a summation of figures derived from a number of corporate travel management company sales. 
As the accuracy of the sources of data is of primary concern to management, the management reports enable them to achieve their objectives of greater negotiating power with suppliers and travel policy compliance from travellers. In this the relationship between suppliers, travel agencies/travel management companies, travellers and the organisation is highlighted.

\section{Figure 1 A typical pattern of corporate travel expenditure}

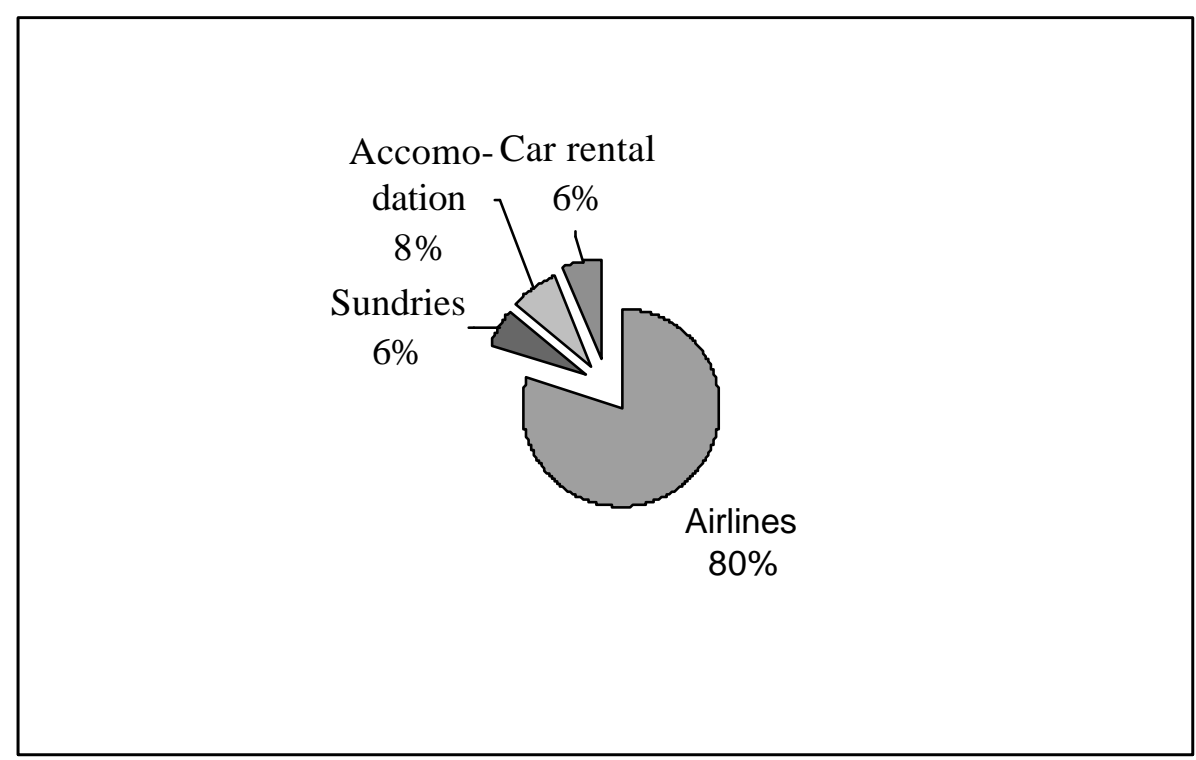

Source: Costa-Gomes and Birns (2003) and a summation of selected travel management company sales 2002

\section{Travel expenditure processing}

Organisations differ in their approach to processing their travel expenditure. Some companies use a central corporate credit card placed in the office of the travel management company for airline tickets. Other travel expenditure is either billed back, where agreements with suppliers have been made, or the traveller reclaims upon his return. Some companies issue corporate travellers with company credit cards or have them use their personal credit cards and reclaim upon return. However, to enable the company to capture travel data, a central system is required. The corporate card can serve this purpose. The corporate card represents a single payment system whereby the organisation is issued with a business travel credit card from a corporate bank such as Diners Club or American Express. Credibility and efficiency of suppliers in this travel expenditure process is paramount to an effective corporate travel management programme. 


\section{The travel management company}

Organisations must consolidate their travel buying with a preferred travel management company, agreeing on the management, transaction or service fee, defining the service specifications and buying requirements and at the same time monitoring performance (Bunge, 2001). Organisations without an effective travel management programme have generally made their travel arrangements through one or more retail travel agencies. An effective corporate travel management programme requires the services of a travel management company rather than a travel agency. The evolution of retail travel agencies to travel management companies has been swift with retail travel agencies still existing to serve the leisure market and individual business travellers. However, those serving corporations have had to adjust their focus, service and operations. The major shift has been to becoming agents acting on behalf of the client rather than agents acting on behalf of the supplier. In the past (and still today) corporate secretaries contacted the travel agency by telephone and provided the details of the corporate traveller's itinerary, whereupon the travel agent did the reservations. The travel agency earned 9 per cent on international airfares and 7 per cent on domestic airfares. Many travel agencies and particularly those serving the corporate market had agreements in place with preferred suppliers for overriding commissions when pre-set sales levels were achieved by the agencies. Travel agencies handling corporate clients with a substantial travel budget were generally travel agencies with branches throughout the country and in-house agencies were established to secure, as far as possible, a corporate travel account. Suppliers were the primary source of revenue and agencies were the main channel for suppliers to reach corporate clients. In these circumstances, the relationship between suppliers, travel agencies and corporate clients could be described as linear as depicted in Figure 2.

\section{Figure 2 The relationship between suppliers, travel agencies and corporate clients: a linear relationship}

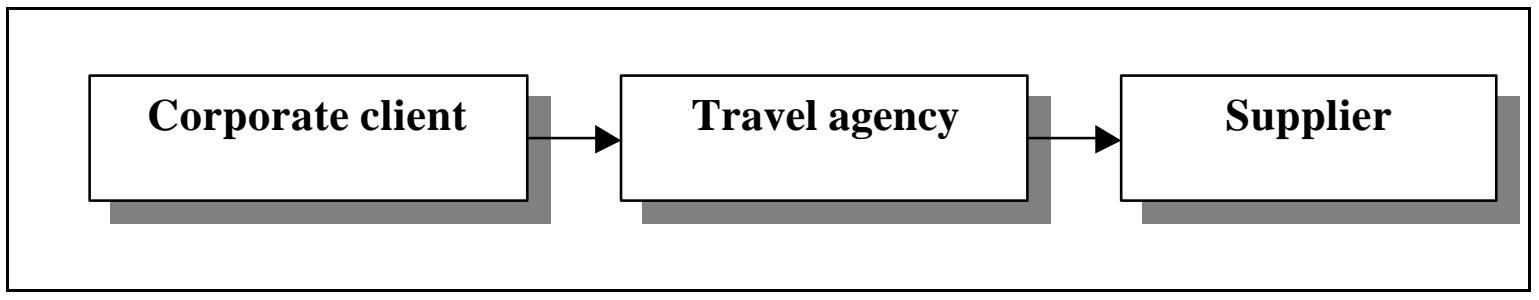

More recently, with technological advances such as the Internet and commission cutting, where the agent in South Africa earns a basic commission of 7 per cent on both international and domestic airline sales, the relationship has had to change. Corporate clients have focussed far more on cost management and obtaining value for money, not only in terms of products and services, but also 
in demanding added value from the travel agency. The travel agency has had to re-evaluate the nature of its service and move from being an "order-taker" mainly receiving and processing bookings, to also providing value added services such as management information systems on travel patterns and expenditure; travel policy adherence; negotiating client-focussed preferred supplier agreements; cost containment and budgeting. Travel agencies have therefore evolved into travel management companies. The revenue structure of this evolving travel management company has also had to change. The focus has shifted from the supplier as the only source of revenue; to the client who, on the basis of the value-added service provided by the travel management company (TMC) negotiates a management fee where the client as well as the TMC can benefit. Revenue earned by the TMC is not as simple as that of the retail travel agency earning commission or service fees from independent leisure or business clients. A TMC must negotiate with their corporate client, as part of their partnership agreement, on how they will be paid. The revenue earned can range from commissions paid by suppliers, to a negotiated fixed management fee paid by the organisation or profit sharing between the organisation and the agent based on the savings achieved on travel expenditure. Agreements on fees are based on the types of services required by the organisation and are generally negotiated on a contractual basis. In this changing relationship the supplier is seeking the highest possible yield, reducing its distribution costs by cutting commission to the agents and seeking exclusivity in the use of its services by negotiating corporate agreements with corporate clients. The relationship under these circumstances can be described as circular as depicted in Figure 3.

Figure 3 The relationship between suppliers, travel agencies and corporate clients: a circular relationship

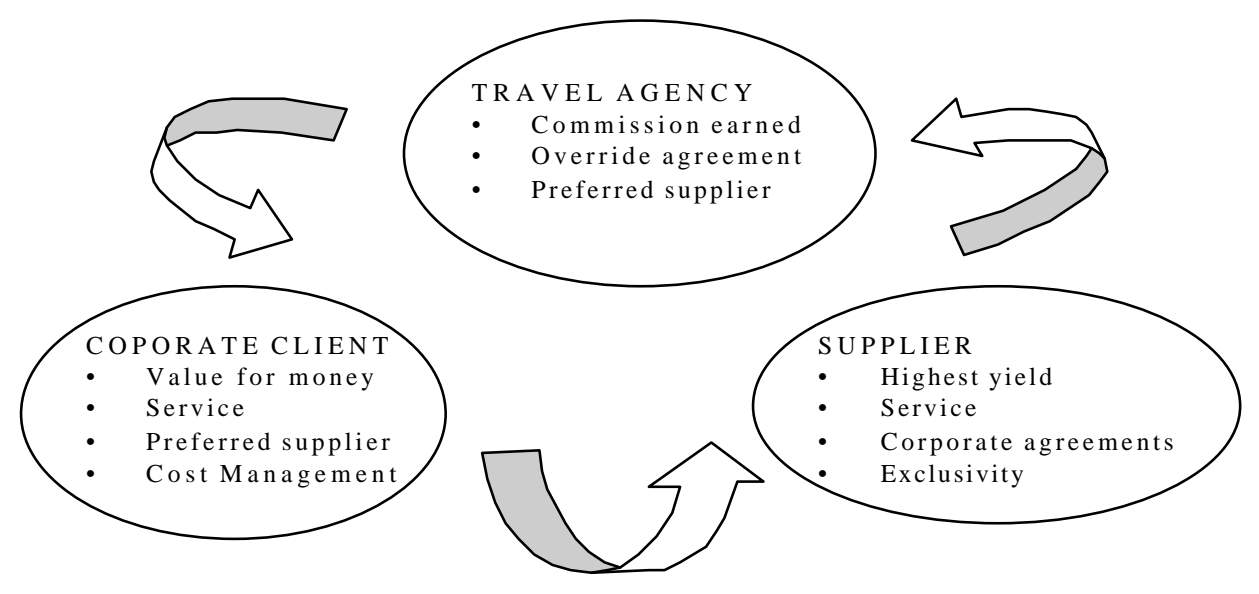


With continuing technological advances in the use of the Internet and systems such as mobile technologies travel management companies increasingly have to compete with suppliers who have far greater direct access to the client than ever before. Under these conditions the managing director of Seekers Travel South Africa, Jonathan Gerber, says that the future of travel management lies in a partnership approach (depicted in Figure 4) between the TMC and the corporate client on the one hand, where they share a common goal, seek value for money, share in achieving a desired level of service, managing costs and jointly negotiating best deals, and preferred suppliers on the other hand.

Figure 4 The relationship between suppliers, travel management companies and corporate clients: the partnership approach

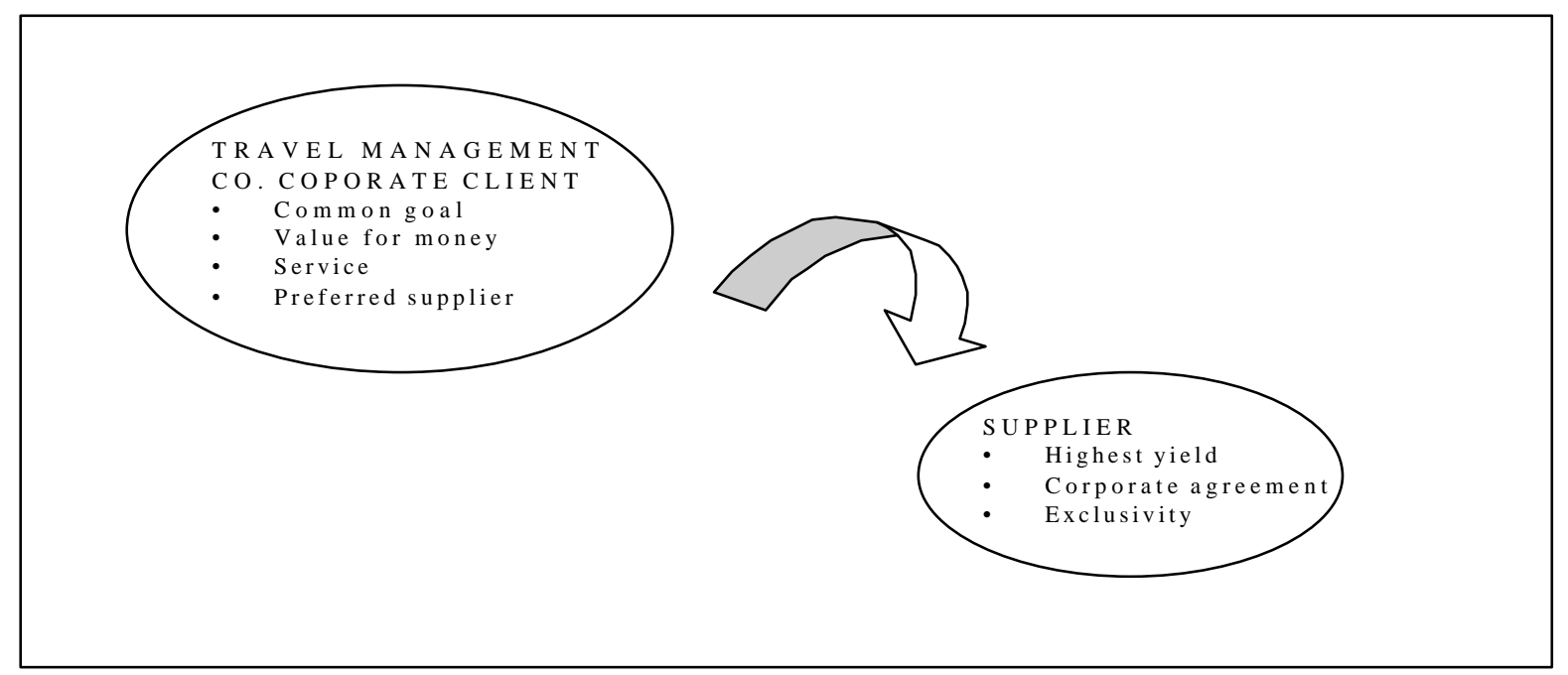

In determining to what extent South African organisations implement corporate travel management programmes and their perceived effectiveness, a research project was undertaken. This research covered the four core elements of a corporate travel management programme as identified in the literature: a travel policy; travel data, a travel expenditure processing system; and, a contracted travel management company. The research also covered the use of technology by corporations, which is regarded as central to the entire process of corporate travel management (Wilkinson, 2001).

\section{RESEARCH OBJECTIVES}

The research project investigated the current status and trends in corporate travel management in South Africa by analysing the management and control of travel expenditure in terms of each of the elements identified, with the aim of developing a management model for effective corporate travel management. The following research objectives were identified: 
- To determine the organisation of travel management in South African corporations.

- To evaluate travel policy compliance by travellers of the selected South African corporations to highlight possible conflicting values

- To identify sources of travel data, the objectives and their accuracy

- To determine which travel expenditure processing system is used

- To establish the perceptions, concerns and expectations of corporations on value-added services of travel management companies to highlight possible conflicting goals

- To introduce a conceptual management model for effective corporate travel management.

\section{METHODOLOGY}

A quantitative ex post facto survey was undertaken. A questionnaire was sent to the individual concerned with managing the corporate travel function at each of 350 South African corporations registered on the Association of Corporate and Travel Executives (ACTE) South African database. These individuals were either officially designated as corporate travel managers or appointed to manage corporate travel as part of their designated function, which ranged from that of financial director to purchasing or procurement manager. The selected organisations have a substantial travel spend and are spread over diverse industries. This population was selected because membership of and participation in ACTE forums indicate awareness (and willingness) by these organisations to effectively manage corporate travel. Structured qualitative interviews with suppliers and travel companies were conducted, together with an assessment of current and available online booking tools and other electronic channels in preparation for the formulation of the questionnaire. The questionnaire was pre-tested on a small group of companies and then dispatched in electronic form. To ensure the highest possible response rate an incentive prize of two return airline tickets from South Africa to Switzerland, sponsored by Swiss Airlines, were given in a lucky draw. Follow-up of non-respondents was done telephonically with a second round of questionnaires being dispatched where necessary. Data-analysis primarily included the use of descriptive statistics of variables to assess the current state of travel-related activities in the selected South African corporations; the organisational placement of corporate travel; the implementation and compliance of a travel policy; the quality of travel data; the use of travel management companies and their level of service; the billing system; current technology used; and the perceptions, concerns and expectations of corporations with regard to emerging technologies. Crosstabulation was used for comparing across size of organisations and current travel 
processes. Chi-square tests were done to establish correlation between variables and statistical significance of results, where applicable

\section{RESULTS}

The questionnaire was successfully sent to 350 electronic mail addresses and 109 responses were received, with 3 being unusable, this represents a response rate of 30 per cent, which is considered good if the length of the questionnaire is taken into account. For the purposes of this article, and mainly due to length limitations, only certain relevant findings are presented.

\section{Corporate profile}

Through the use of frequencies it was established slightly more South African owned organisations were surveyed than international organisations with offices in South Africa. The two main types of organisations surveyed were public companies and private companies with a small number being parastatals and only a few being government departments. It was found that the organisations were spread over a diverse number of industries with the most being found in the manufacturing and financial services industries. Travel expenditure of the organisations ranged from approximately R1 million to as much as R300 million. For purposes of further analysis organisations were categorised into two groups: those with a travel expenditure of less than R10 million and those with a travel expenditure of more than R10 million. This provided two groups of approximately the same size.

\section{The corporate travel management function}

As corporate travel becomes more specialised organisations are increasingly formulating a corporate travel strategy that is implemented through the development of a corporate travel management programme. The four cornerstones of travel management underpin this programme: a travel policy; a travel information system; a travel expense processing system; and a contracted travel management company.

The results from the frequency analysis shows that the companies surveyed generally have a corporate travel strategy and centralise the travel function under a specific department. In cross tabulation (as shown in Figure 5) it was significant that where organisations have a corporate travel management strategy, they are more likely to centralise the travel function as opposed to those organisations that do not have a strategy in place. 


\section{Figure 5 Cross tabulation of respondents with a centralised travel management function by the presence of a corporate travel management strategy}

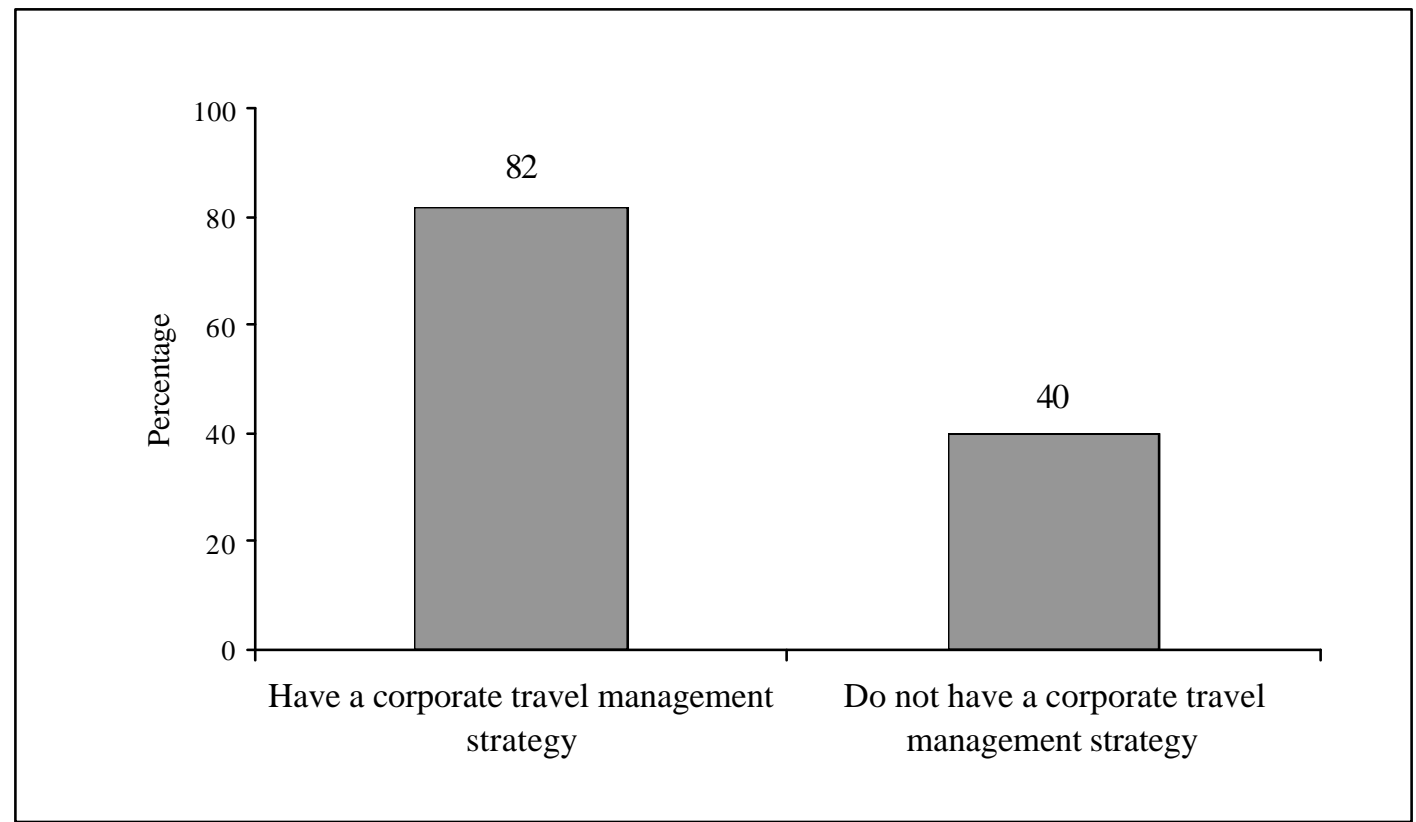

An interesting result from the frequency analysis was that while centralisation does occur and strategies are in place, the time spent by the manager designated to travel management is in most instances not the major part of his task with only 8 per cent indicating that they spend all their time on travel management.

Organisations that have an increasing travel volume tend to move towards some form of consolidation or centralisation of this function. This consolidation often takes place under an existing department such as Procurement or Finance. One of the primary functions of such a department is to consolidate the travel volume to obtain leverage from travel providers such as airlines, hotels and car rental firms in the negotiation of contracts at reduced prices, this is generally seen as the domain of the Procurement Department and thus travel management becomes part of it. On the other hand, the increasing pressure to control travel expenditure makes it a logical choice for management by the Finance Department. Organisations may also consolidate the travel function under a separate corporate travel department. As shown in Figure 6 the results from this study indicated the same trend in the placement of the corporate travel function. A separate department for corporate travel was indicated by approximately one quarter of respondents, with slightly more respondents showing travel management as part of Procurement and slightly less as part of Finance. This confirms that these are the three most logical options for the location of corporate travel. The rest, as shown under others, ranged from no allocation to the Marketing Department or Human Resources Departments. 


\section{Figure 6 Organisational placement of corporate travel management}

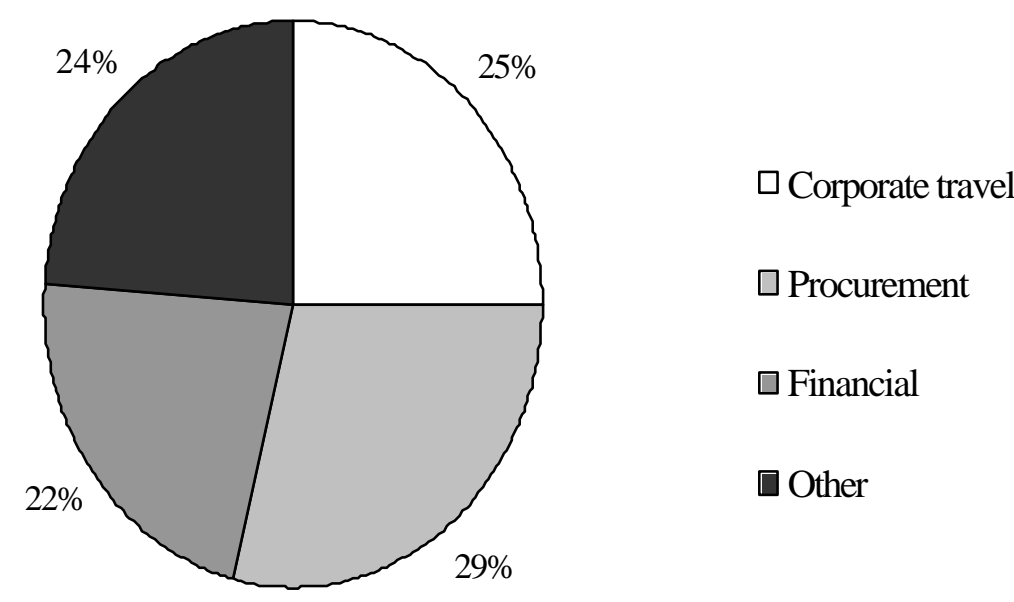

\section{Travel policy}

The first step in effective travel expense management is to establish a comprehensive travel policy within the organisation that maintains high levels of productivity and morale. The next logical step is to effectively monitor travellers' compliance with the policy. If travellers do not comply with the policy, reasons should be sought so that the causes can be dealt with.

The frequency analysis showed that most policies have been in place for longer than two years, are available in a formal and written format, mostly available online and updated as necessary or continuously. As shown in Figure 7, only 22 per cent of organisations reported that travellers comply with the travel policy all the time. While 73 per cent of organisations believe that there is compliance most of the time, this does highlight that problems in compliance do exist. 


\section{Figure 7 Travel policy compliance}

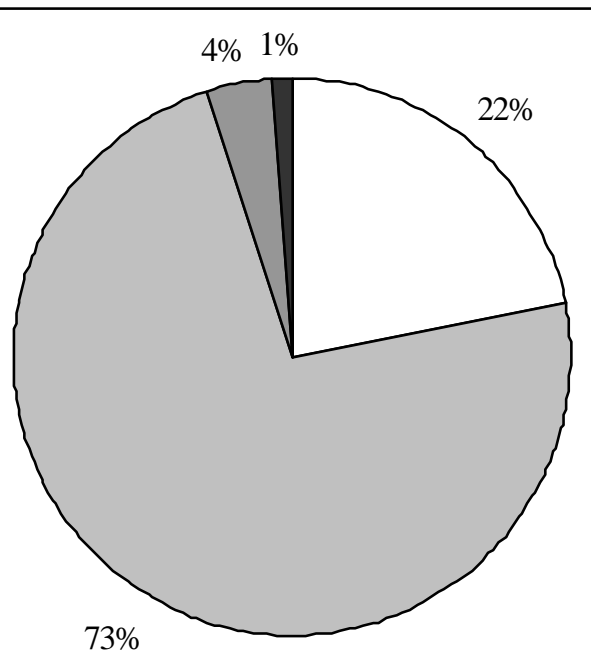

$\square$ All the time

$\square$ Most of the time

$\square$ Some of the time

$\square$ Rarely

More than half of the organisations reported that non-compliance was found in the area of meals and entertainment expenditure with approximately equal numbers reporting non-compliance in airline and accommodation expenditure. The two areas where the least number of organisations experienced noncompliance were car rental and travel approval procedures (Figure 8).

\section{Figure 8 Areas of non-compliance}

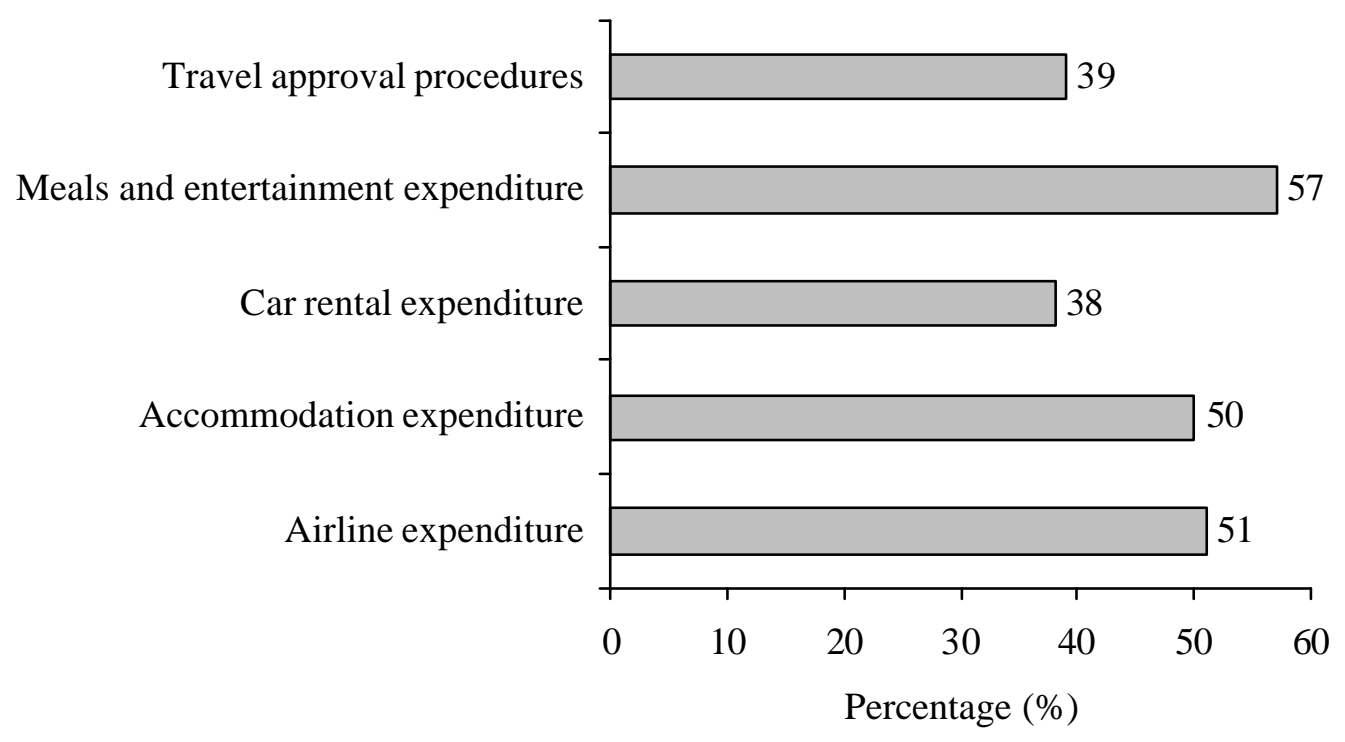

As shown in Figure 9, most organisations are of the opinion that last minute bookings are a reason for non-compliance with almost the same number agreeing that unknowing infringement by travellers is a reason. The use of personal loyalty cards was also indicated by more than half of respondents as 
being a reason for non-compliance. An interesting result is that of deliberate infringement by travellers (41 per cent), which suggests that policy monitoring is a problem or travellers are unsatisfied with policy content.

\section{Figure 9 Reasons for non-compliance of the travel policy}

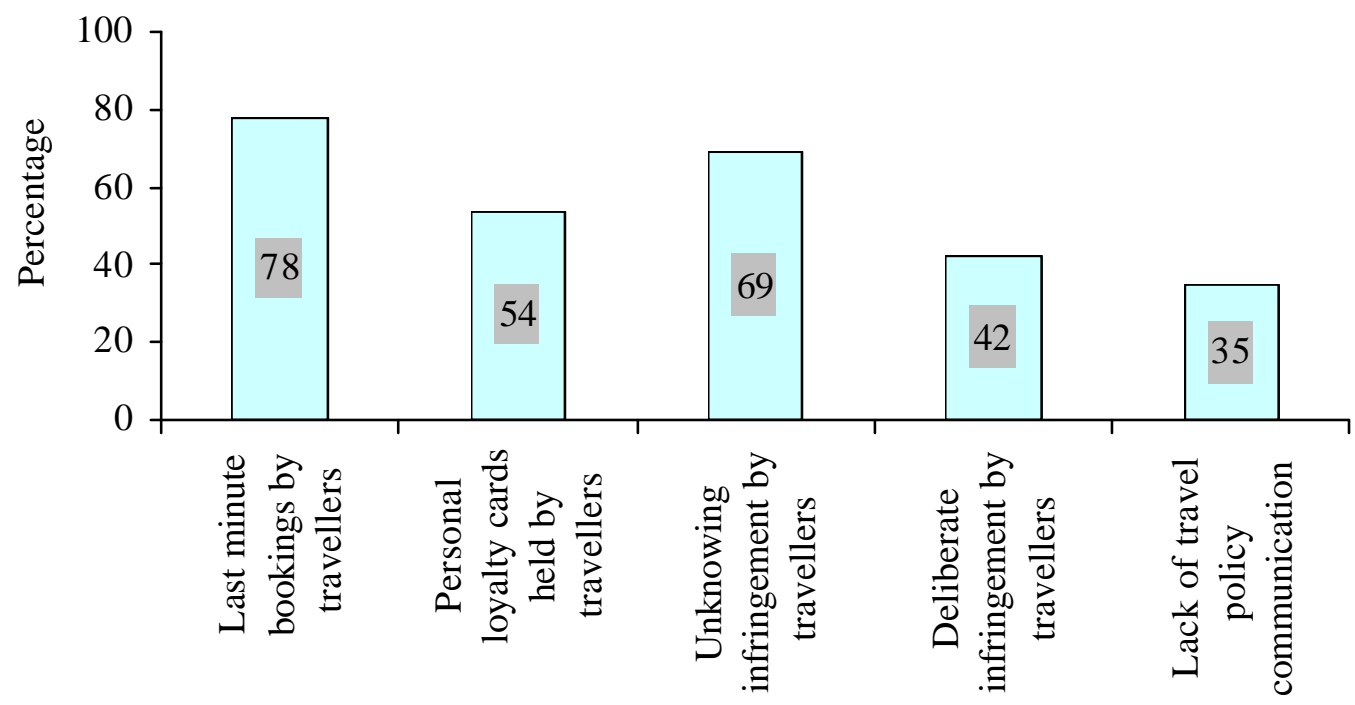

Figure 10 shows that a significant difference was indicated between public and private companies with more public companies reporting deliberate infringement as opposed to private companies.

Figure 10 Cross tabulation of deliberate infringement by public and private companies

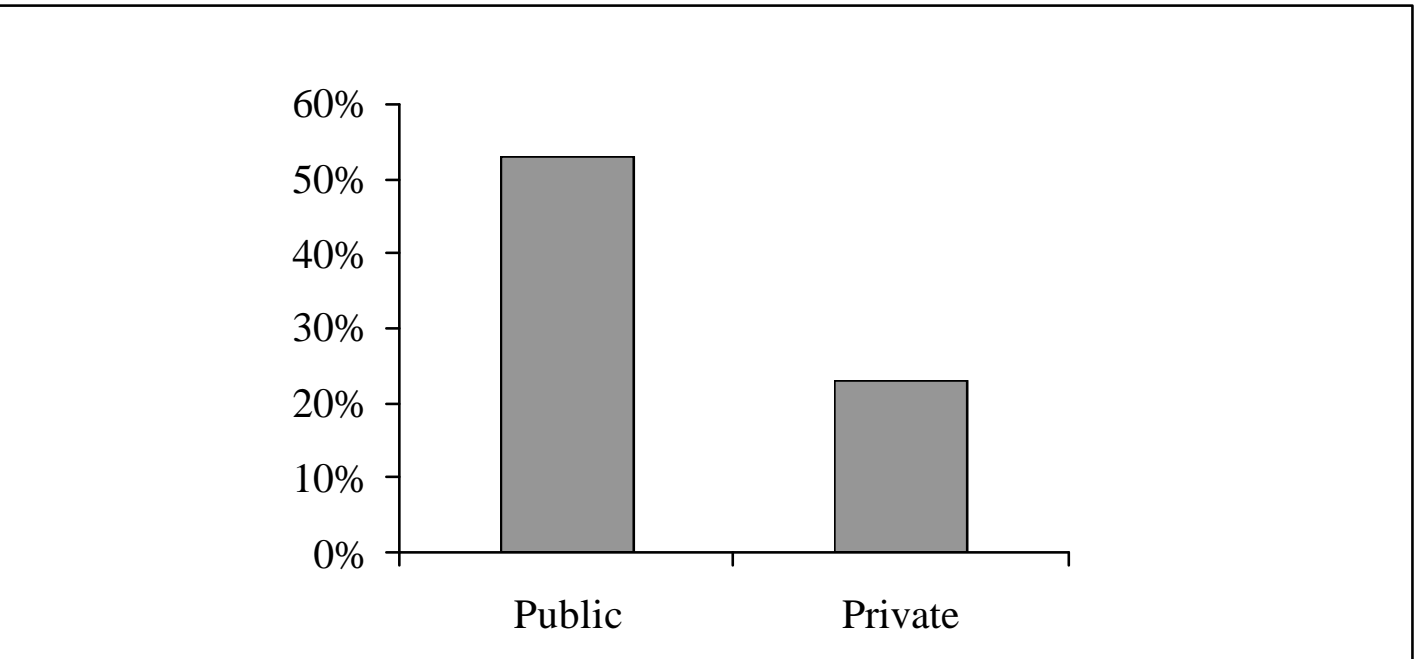


The question of more public companies experiencing deliberate infringement of the travel policy by travellers raises a number of questions:

- Is travel policy monitoring less effective in public companies?

- Are public companies prone to greater abuse of travel benefits by travellers?

- Are private companies more concerned with controlling travel expenditure?

\section{Travel management information}

Most respondent organisations indicated that they obtain their travel management information from sources such as travel agency reports, their own financial accounting systems (these proved to be the sources used by the most organisations in this study), corporate card expense reports, dedicated information systems, supplier reports and expense processing systems. Organisations may use more than one source of data.

As shown in Figure 11, the majority of organisations regard their travel data as important mainly to control travel expenditure and increase negotiating power with suppliers. This supports the proposition that these are the two main reasons for formulating a corporate travel management programme. Other reasons mentioned are: to understand employee travel; and to redirect travel expenditure to fulfil supplier agreements.

\section{Figure 11 Objectives of travel data}

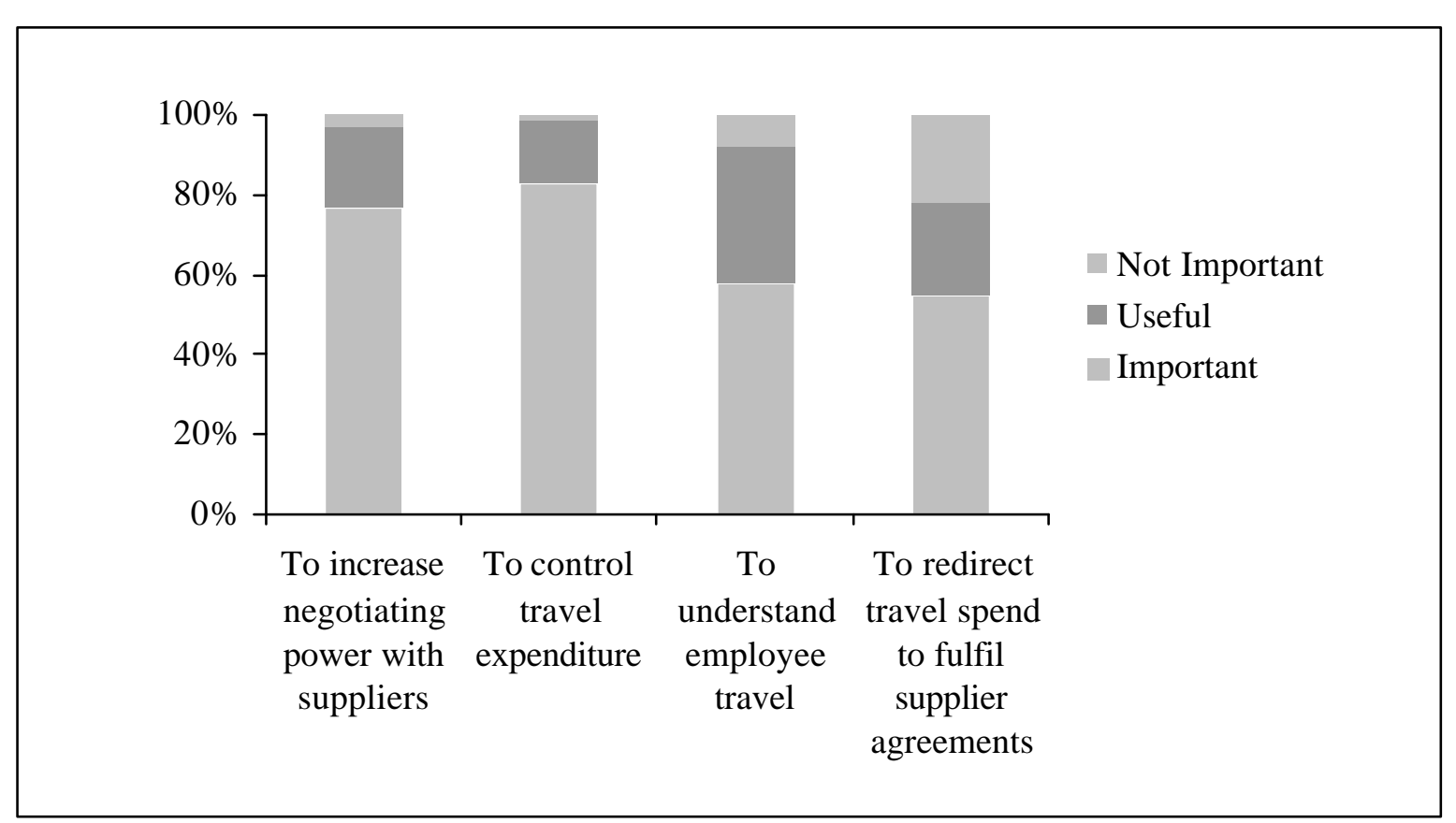

The results show a significant difference in the use of certain sources of data between organisations that have a corporate strategy and those that do not. 
More organisations with a corporate travel strategy make use of travel agency reports, corporate card expense reports and supplier reports as sources of data than do those organisations that have no corporate travel strategy, as shown in Figure 12.

\section{Figure 12 Cross tabulation of sources of travel data by corporate travel strategy}

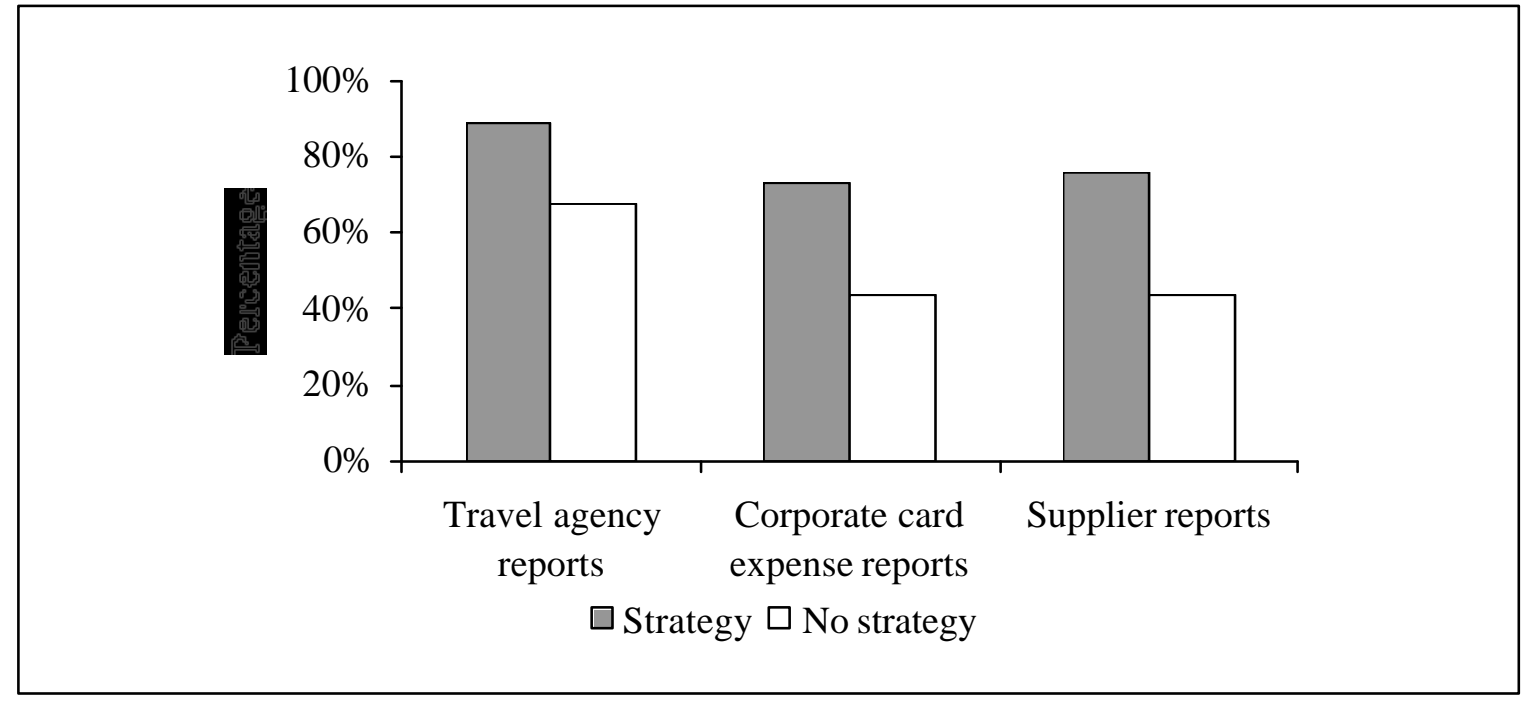

As shown in Figure 13, it would appear that the general standard of accuracy of the sources of data is good or acceptable to the majority of respondents, with the highest number of organisations regarding the financial accounting systems as accurate. The question on the accuracy of travel data reports was regarded as essential as it may show some link to problems experienced in controlling travel expenditure and highlight problems with suppliers or travel agencies. This result shows that more respondents regard internal sources of data as accurate than they do the external sources. 


\section{Figure 13 Accuracy of sources of travel data}

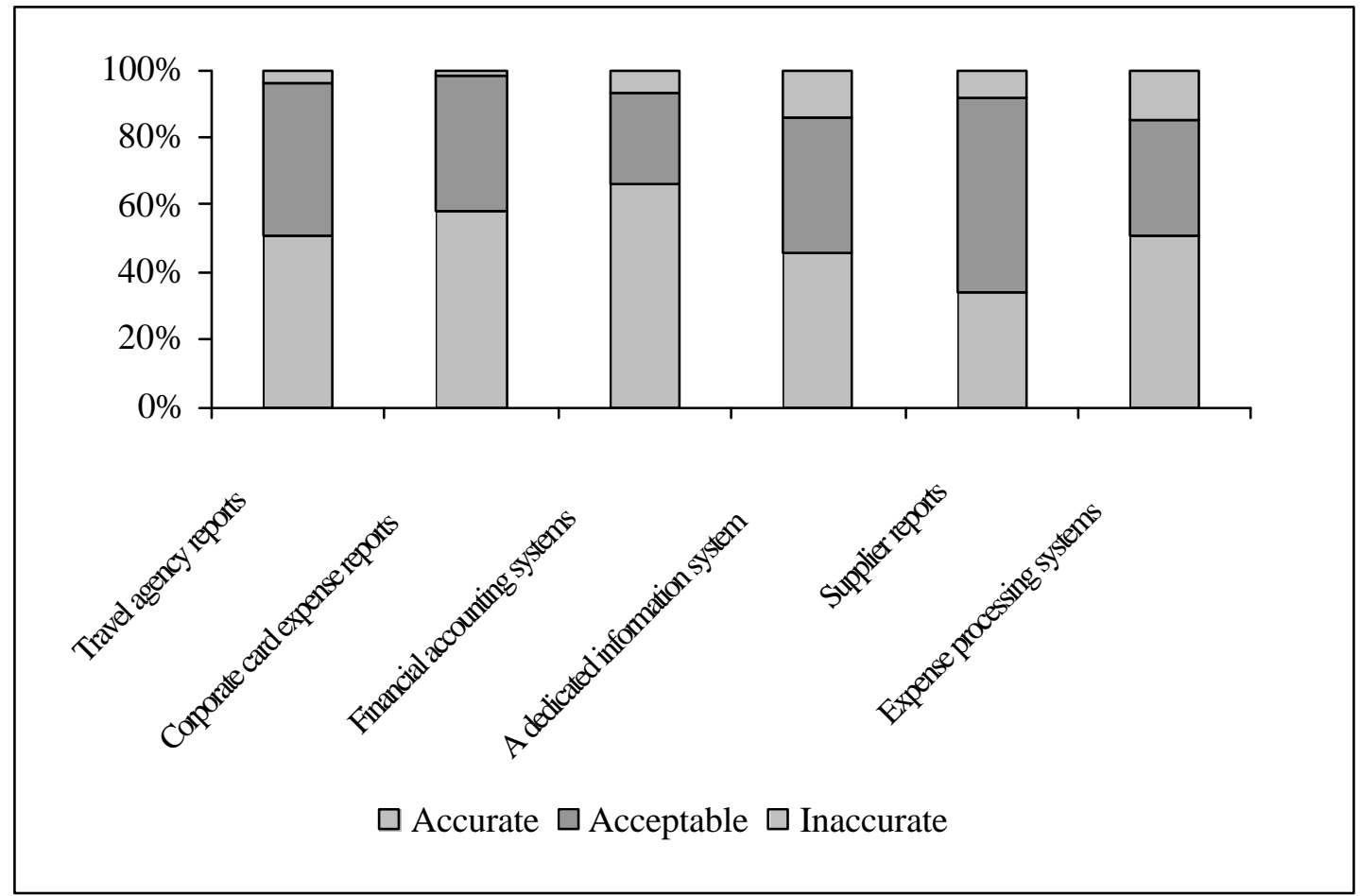

\section{Travel expenditure processing}

Organisations differ in their approach to centralizing their travel expenditure processing. Figure 14 shows that in this study most organisations use the bill back system. Some companies use a central corporate credit card placed in the office of the travel management company for airline tickets. Some companies issue corporate travellers with company credit cards or have them use their personal credit cards and reclaim upon return. It is evident that organisations use more than one system for travel expenditure processing. The complexity of the various systems may have implications for travel expenditure control and travel policy compliance. 


\section{Figure 14 Travel expenditure processing}

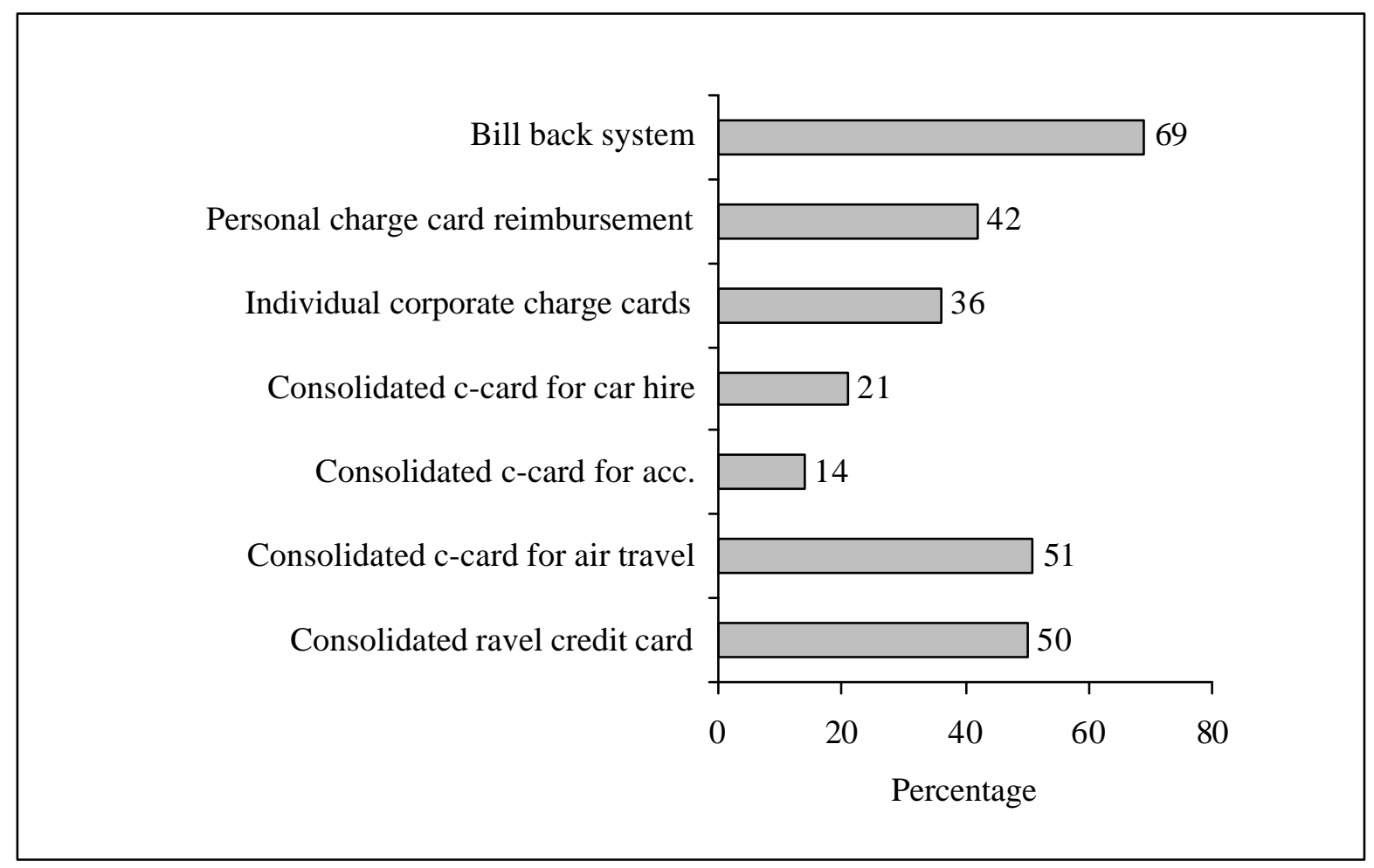

\section{The use of travel management companies}

Currently 89 per cent of organisations use travel agencies/travel management companies (either in-house or outside) for travel arrangements and other travelrelated services (Figure 15). Of the remaining organisations 2 per cent work through suppliers and 9 per cent work through both travel agencies and suppliers.

\section{Figure 15 Most used distribution channel}
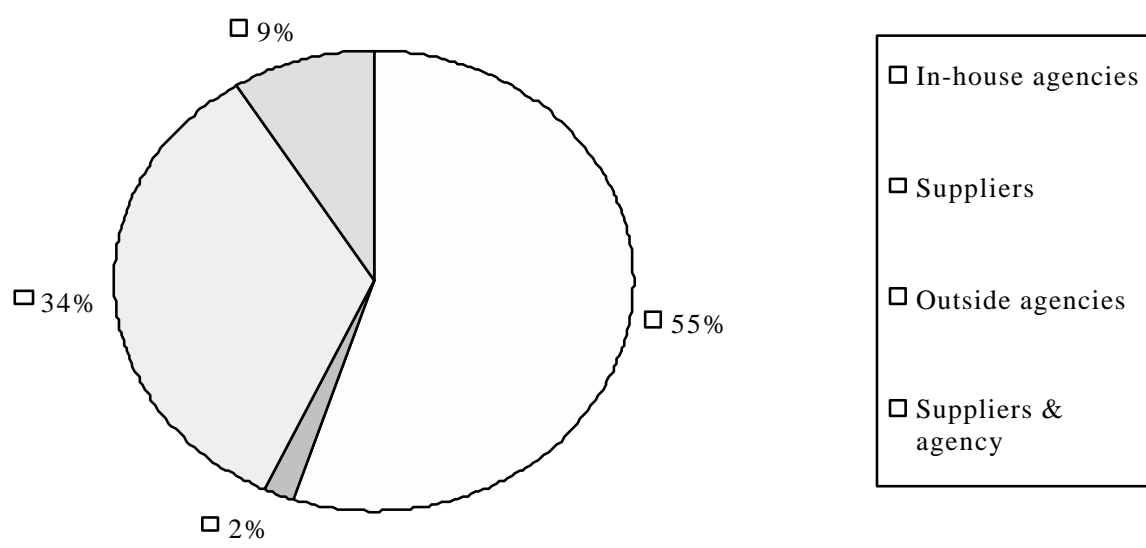
Figure 16 indicates how organisations perceive the level of service provided by their travel agencies. The service level of travel reservations is considered to be good or acceptable by most respondents. Services such as travel advice, policy development and supplier negotiations show more diversity of opinion. In a number of instances the organisation's travel agency does not provide the service at all, for example, in summaries of car rental expenditure, policy development, compliance and monitoring and technology support and access. Where the service is provided the percentages ranged from good to no service, particularly if a comparison is made between services such as reservations, travel advice and technology support and access.

\section{Figure 16 Service levels of designated travel agency}

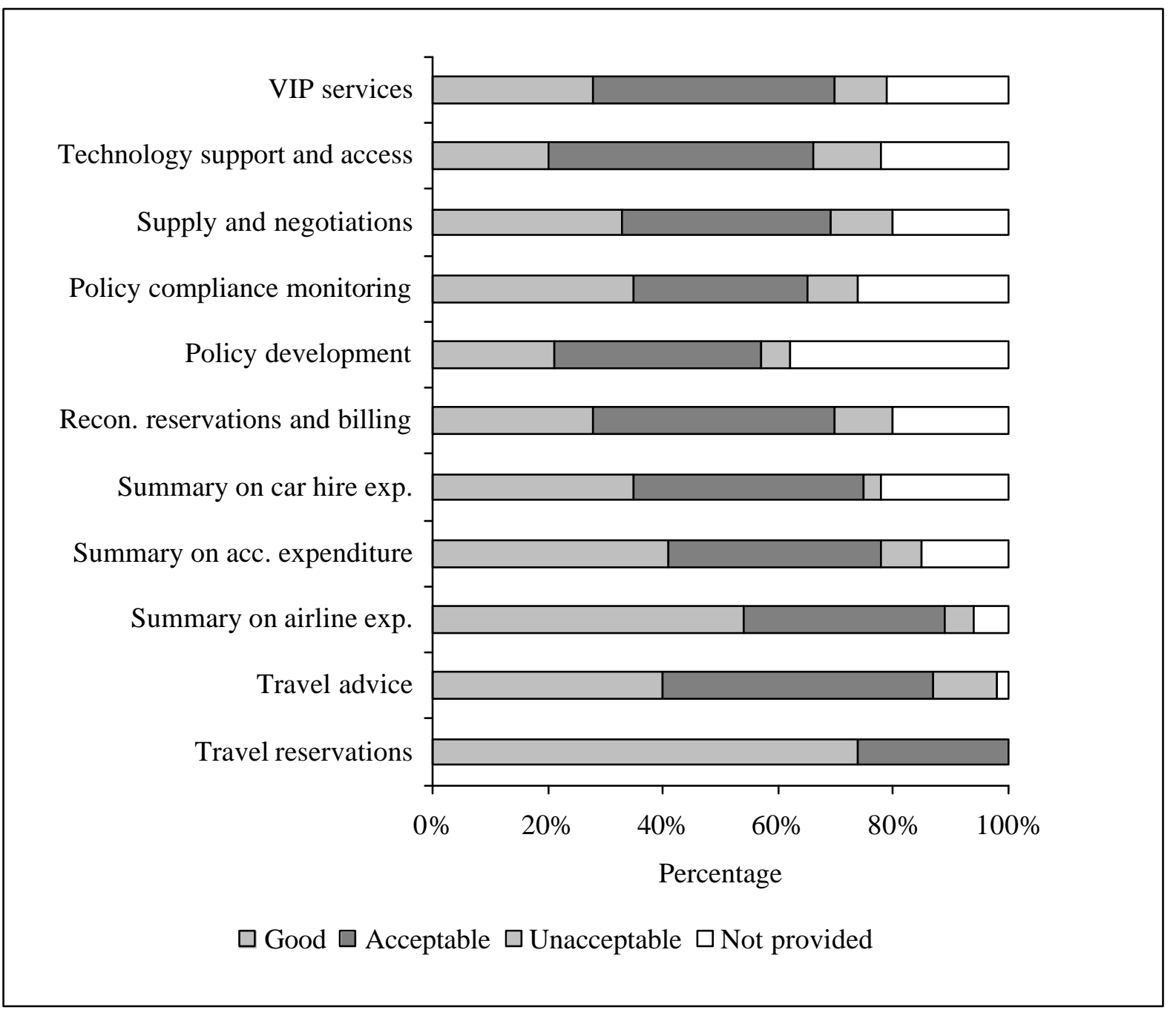

As far as the revenue agreements with travel agencies, Figure 17 shows that there is a significant difference between types of revenue agreements selected and the size of the organisations annual travel expenditure. Management fees are selected by a greater number of organisations that have an annual travel spend of more than R10 million. This is also true where two types of 
agreements are used, for example management fees and transaction fees. Substantially more organisations with an annual travel spend of less than R10 million have transaction fee agreements in place whereas approximately the same number of organisations from both categories has no agreements in place.

Figure 17 Cross tabulation of revenue agreements with travel agencies by travel expenditure

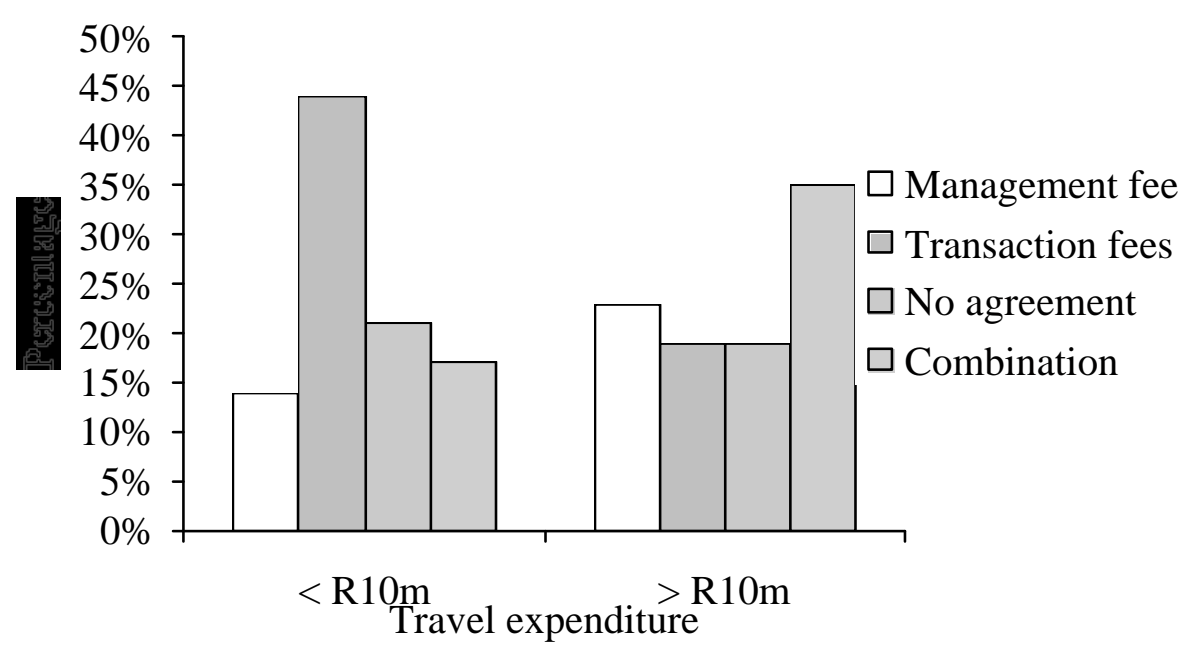

As shown in Figure 18, although most organisations believe that the revenue agreement is to the equal benefit of both parties, interestingly a quarter of respondents indicated that they perceive it to be more in favour of the travel agency. This shows clearly that in some organisations there is a value and goal conflict between the participants in the travel management programme.

\section{Figure 18 Benefit of revenue agreements to organisation versus travel management company}

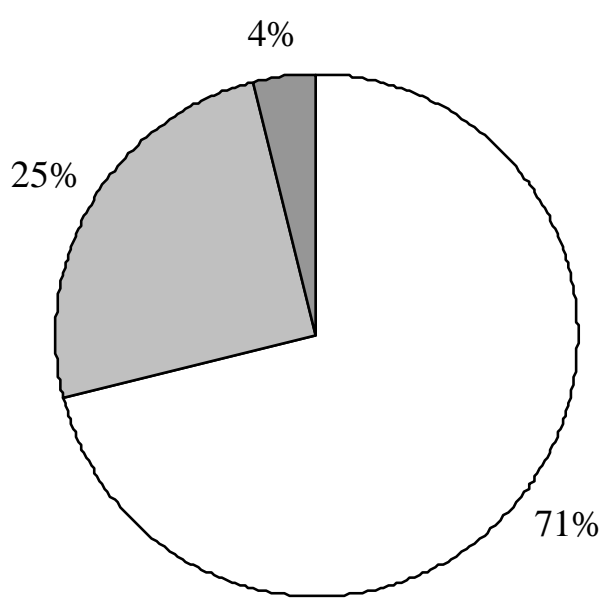

$\square$ To the equal benefit of both parties

$\square$ More in favour of the travel agency

$\square$ Not one of the above 


\section{Critical success factors}

The final section of the study covered the issue of what respondents believe to be critical to the success of a corporate travel management programme. A list of factors was provided and respondents were asked to respond with a "yes", it is critical, "no", it is not or "I don't know" whether it is or not. In determining what the respondent considered to be critical success factors, almost all agreed on the factors as shown in Figure 19. Critical success factors where practically all appeared to be in agreement were negotiated agreements with suppliers; travel expenditure control; top management support and comprehensive and accurate travel data. The majority was in agreement on all the other factors and where respondents were asked to provide any further critical success factors, none of any significance was provided.

\section{Figure 19 Critical success factors for effective corporate travel management}

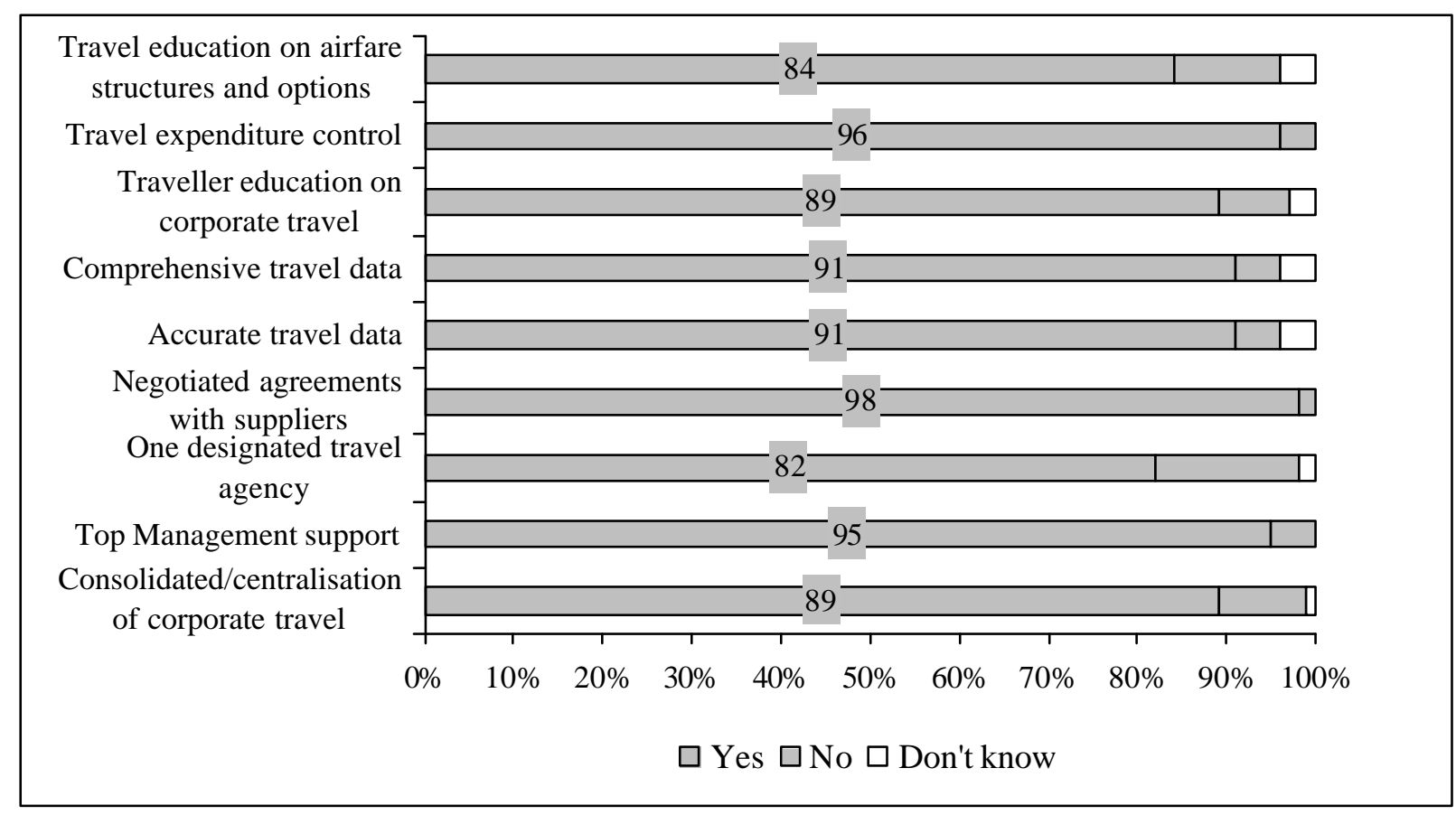

In determining the use of technology for travel arrangements, the frequency analysis showed that while approximately half of the respondents use some form of Internet-based system (for example supplier websites or online corporate selfbooking systems) only 12 per cent of respondents use the online self-booking systems. As far as critical success factors and technology is concerned, an interesting result found was on the question of whether organisations regard corporate self-booking systems that are linked to suppliers and travel agencies as a critical success factor in effective corporate travel management. While only 32 per cent of all respondents regard this as a critical success factor and 13 per cent indicated that they do not know, a substantial difference of opinion was found 
between the "user" (those organisations that use some form of online system for travel reservations and management) and "non-user" (where respondents either use the Internet for enquiries or information only or who use no computer-based system at all). As shown as shown in Figure 20 in the "user" category more organisations believe it is a critical success factor while in the "non-user" category only half this number believes it to be so. This suggests a difference in expectations regarding the value and benefits of such a system and may be one of the reasons for "non-users" not actively pursuing changes in technology to become "users".

\section{Figure 20 Is corporate self-booking system a critical success factor?}

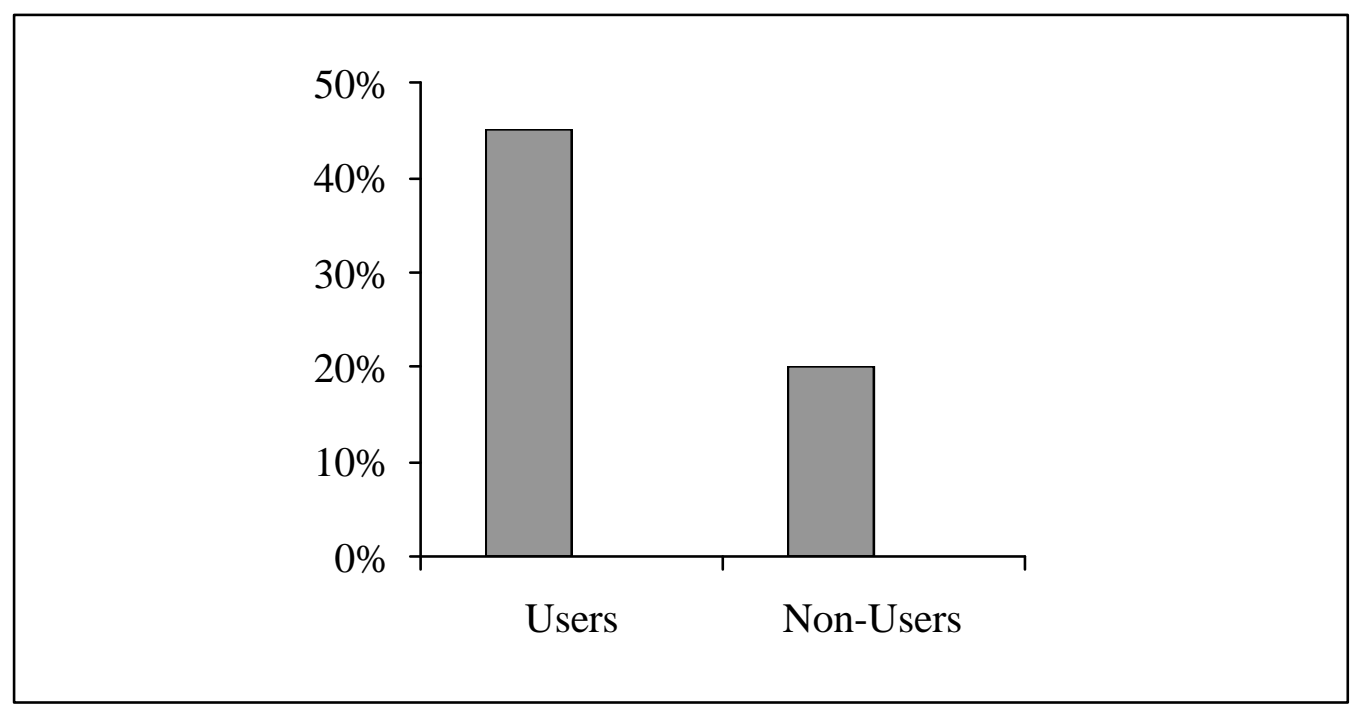

\section{Synthesis of research findings}

In summary of the results, this research shows that corporations generally have a corporate travel management strategy and programme in place. An overwhelming number of respondents were in agreement on the critical success factors, which showed that suppliers and travel management companies play a major role in its success and that top management support is essential. Corporate travel agencies/travel management companies are still perceived to be the most effective reservations channel although there is some conflict indicated in terms of revenue agreements. There is, however less satisfaction with their ability to offer travel advice, provide travel data, assist with policy development and compliance, conduct supplier negotiations and provide technology support. The research found that the majority of corporations believe that the role of corporate travel agencies should change to that of travel management companies. Although only a small percentage of corporations are using corporate self-booking tools and supplier websites, an increase over the previous year was indicated. This, together with the perceived advantages of technology, and efforts to overcome current application and integration 
problems, should serve as warning signals to corporate travel agencies. Corporate travel agencies are expected to provide value-added corporate services with the necessary effective technology access and support in order to maintain their position as the preferred channel. With continuing technological advances and systems such as the Intranet and mobile technologies, travel management companies increasingly have to compete with suppliers who have far greater direct access to the client than ever before.

\section{A CONCEPTUAL CORPORATE TRAVEL MANAGEMENT MODEL}

In conceptualising a management model for corporate travel management, the results from the empirical research was taken into account which highlights some of the problems of conflicting values and goals between internal partners (for example, between management and travellers in policy compliance) as well as external partners (for example between the organisation and the TMC in terms of service levels). The model thus had to take a number of factors into account:

- The various role-players and the nature of their relationship with the corporation (internally this means management and travellers and externally, suppliers and travel management companies);

- The goals of the travel programme and desired outcomes (travel expenditure control through travel policy compliance and expenditure processing as well as effective supplier negotiations);

- The components of the travel programme (policy, data, expenditure, suppliers/travel management companies).

A model that appears to fulfil many of the characteristics of corporate travel is the so-called "soft value management model" (Liu \& Leung, 2002) and is proposed as a foundation for further testing and evaluation in ensuing studies. This model was specifically described in the context of project management in the engineering field but the underlying elements of this model are similar to those found in corporate travel management. A brief theoretical overview of this model as depicted in Figure 21 states that value management is represented by the input of internal (personal/individual values) and external factors (environmental pressures) that triggers a decision-making process producing decision outcomes. This leads to the definition of project goals. The transformation of values into goals - as a decision-making process - comprises objective setting, objective analysis and alternatives evaluation. The goals being set will initiate required action towards project realisation. Goals are underpinned by an individuals value system. What the person attaches value to affects the content specificity of the goals set. When more than one individual is involved in goal setting (as is the case in corporate travel management), value 
conflict may lead to goal conflict. Agreement on value standards between individual participants, referred to as "value specificity", is a prerequisite to agreement of goals, also referred to as "goal specificity". The nature of the conflict (which may be inter- and intra-personal) arises from the expected probabilities of alternative actions and possible outcomes. This conflict may be latent or manifested in behaviour patterns and should be brought forth, supporting participative and creative problem-solving and stimulating the desire to transform value specificity to goal specificity. "People are more easily committed to performance with specific goals; vague goals have shown to have a deterrent effect on high performance" (Liu \& Leung, 2002: 345). Feedback is part of the goal-action-outcome cycle that guides the individuals' behaviour (through considerations of options/alternatives) towards goal attainment, and also provides a basis for assessing the project outcome. In determining the success of a project the individual considers the utility of its success/failure and the level of his/her satisfaction/dissatisfaction. Satisfaction is measured in terms of what the person wants to gain and or keep in the outcome and goal attainment.

\section{Figure 21 A soft value management model}

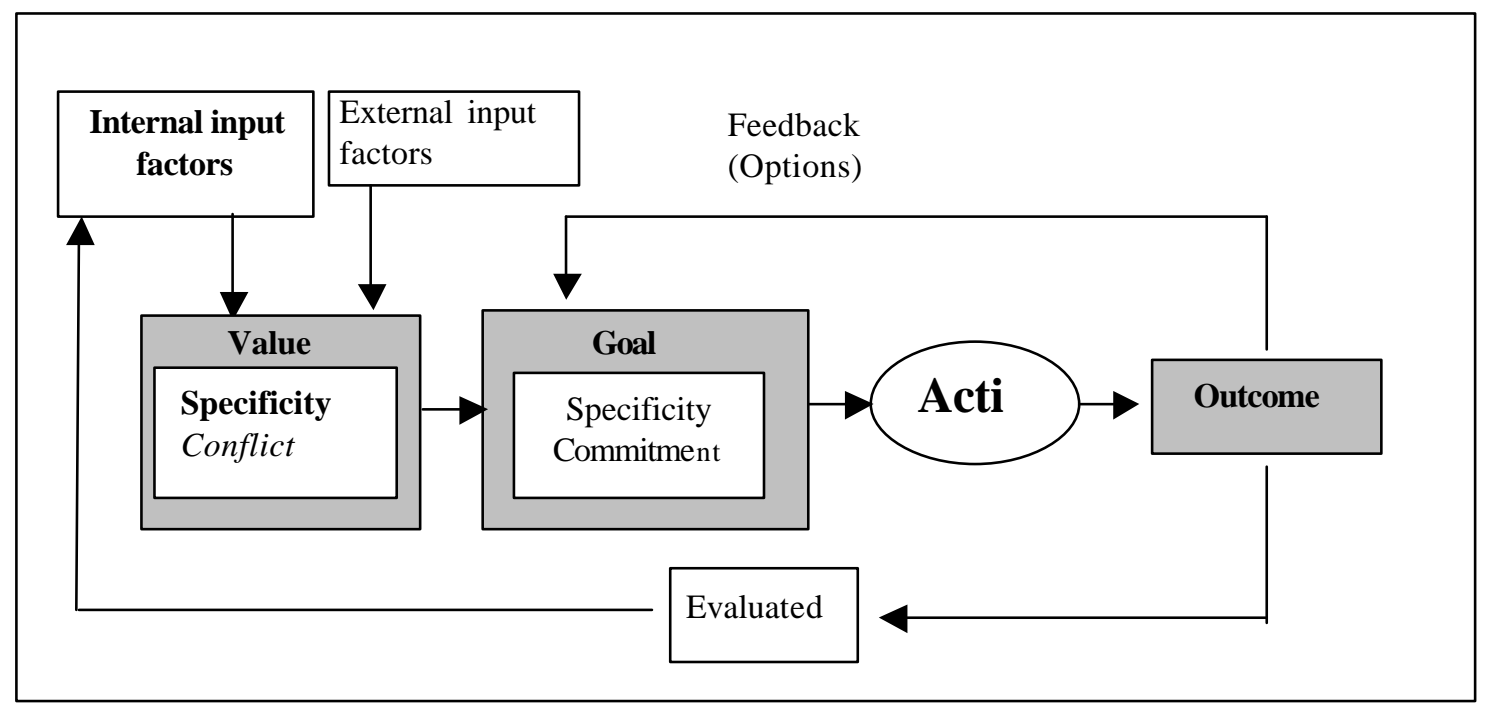

Source: Adapted from Liu and Leung (2002: 346)

In proposing that this model form the basis for a corporate travel management model, a theoretical discussion on the way in which the elements of corporate travel match the elements of the soft value management model is provided. The overall goal of corporate travel departments is to control travel-related corporate spending (Anderson, Lewis \& Parker, 1999). In the pursuit of this goal, the corporate travel department is dependent on the support of individuals in senior management and the co-operation of corporate travellers (this can be regarded as the internal input), and on the support of travel providers and the travel 
management company (seen as the external input). Value conflicts can occur between the corporation, suppliers and travel management company because corporate clients typically want flexibility in their travel arrangements; airlines and other travel suppliers want to maximise yields by optimising revenue and travel management companies want to service client needs at the lowest cost (Roodt, 2001). Value conflicts also occur:

- Between management and travellers due to cost containment actions versus traveller comfort and "self-esteem" (Gilbert \& Morris, 1995).

- Between suppliers, travel management companies and the corporate client in optimising the travel management process, particularly in the area of technology application, where the client often faces both a traditional channel partner and an electronic commerce channel partner. There is often confusion about which channel they should support because it is not clear whether the electronic commerce partner will be successful in the long term or if the traditional channel partner will be able to re-establish itself. According to Subramani and Walden (2000) having both a traditional and an electronic commerce partner allows the firm to play one off against the other, with the result that the new partner will not have the same level of incentive to invest in the relationship as he would otherwise.

- Between management and travellers in policy monitoring and compliance (Gilbert \& Morris, 1995).

Value management through specification and agreement of values and goals for effective corporate travel management leads to commitment by all participants to appropriate action and goal attainment.

\section{CONCLUSION AND FUTURE OUTLOOK}

This article serves as a prelude to the future application and testing of the model. This research was focussed on the needs and objectives of management in terms of corporate travel. Future research must include the other two main roleplayers: travellers, their needs and objectives in terms of corporate travel and service providers such as travel management companies and suppliers with their particular needs and objectives. The results of these studies must enable comparison between the three main role-players in corporate travel management in order to specify the values and goals of each. Once this is done the applicability of the soft value management model can be tested where all participants are committed to appropriate action and goal attainment for effective corporate travel management. 
To conclude this article a brief look at the future of corporate travel shows that changes that will probably take place in corporate travel from two perspectives: that of the corporate client and that of the corporate travel agency. Andersen (1998) says that in the corporate market, there will be a move towards the provision of self-booking tools that allow the corporate travellers to book their own travel by making direct contact with GDS or supplier inventory systems. This will be done through corporate intranets accessible via personal computers, personal digital assistants or by telephone, using voice recognition systems. However, there will still be a need for more complex journeys and itineraries to be handled by highly qualified travel consultants. Successful travel agents will therefore have to respond by transforming themselves into global travel management companies serving their corporate clients rather than acting as a distributor for the travel provider. In the corporate market, corporate agents (travel management companies) will retain a number of advantages which will guarantee a continued role for them in the travel management process: First, they remain the cheapest and easiest distribution medium for the airlines; secondly, those with a high level of industry expertise can use their skills to secure the best value deals for their clients or more complex international multileg trips; thirdly, they can help clients implement and enforce travel policies; and finally, they are well placed to capture data about their client's travel patterns and expenditure enabling them to provide management information. In order to maintain their role in the future the travel management company must, according to Andersen (1998), underscore the following fundamental principles:

- Knowing and understanding the individual customer.

- Focusing on the right customer.

- Aligning their products and services with those customers.

- Delivering value through differentiated services.

This article covered the theoretical nature of corporate travel management and the role of the corporate travel management company highlighting its partnership relationship with the corporate client and suppliers. The result of a study on the current status of corporate travel in selected South African organisations was presented and finally a conceptual model was proposed for effective corporate travel management.

\section{REFERENCES}

1 ANDERSEN CONSULTING (1998) "The future of travel distribution", Research Report Executive Summary: 7. 
2 ANDERSON, R.I., LEWIS, D., \& PARKER, M.E. (1999) "Another look at the efficiency of corporate travel management departments", Journal of Travel Research, 37(3): 267-72.

3 BARTHOLOMEW, D. (1995) “Tracking travel costs", Information Week, 538: 92-4.

4 BELL, R.A. \& MOREY, R.C. (1995) "Increasing the efficiency of corporate travel management through macro benchmarking", Journal of Travel Research, 33(3): 11-20.

BELL, R.A. \& MOREY, R.C. (1997) "Are you in the book? Hotel attributes and corporate travel departments", Cornell Hotel and Restaurant Administration Quarterly, April: 55-61.

6 BUHALIS, D. (2003) eTourism, Pearson Education: Essex.

7 BUNGE, R. (2001) "Corporate travel", Presentation to the B Com Tourism Management Honours students at the University of Pretoria.

8 CHIRCU, A. M., KAUFFMAN, R.J. \& KESKEY, D. (2001) "Maximizing the value of internet-based corporate travel reservations systems", Communications of the ACM, 44(11): 57-63.

9 GILBERT, D.C. \& MORRIS, L. (1995) "The relative importance of hotels and airlines to the business traveller", International Journal of Contemporary Hospitality Management, 7(6): 19-23.

10 GOMES-COSTA, I. \& BIRNS, H. (2003) "Zero commission not set in stone says SAA", TIR. 95: 1.

11 LIMONE, J. (2000) "Corporate travel firms bring tools, expertise", Travel Weekly, 59(77): 31-32.

12 LIU, A.M.M. \& LEUNG, M. (2002) "Developing a soft value management model", International Journal of Project Management, 20: 341-49.

13 MASON, K.J. \& GRAY, R. (1995) Short haul business travel in the European Union: A segmentation profile", Journal of Air Transport Management, 2(3/4): 197-205.

14 PALAPIES, F. (2001) "Mixing business with pleasure is becoming more business than leisure", TIR Southern Africa, 75: 19.

15 RAVENALL, C. (2002) "What is travel management? Why do we need it?" Presentation to the Travel Management Forum of ACTE. Johannesburg 27 March 2002.

16 ROODT, A. (2001) "Flight plan", Leadership, September 2001: 61-4.

17 SUBRAMANI, M.R., \& WALDEN, E. (2000) "Economic returns to firms from business-to-business electronic commerce initiatives: An empirical examination", Proceedings of the 21st International Conference on Information Systems, Brisbane, 2000: 229-41.

18 WILKINSON, T. (2001) "Automating corporate travel management", Travel Weekly, 60(34): 10-12.

19 http://getThere.com [May 30, 2002]. 